\title{
Variation in Infection Capacity and in Virulence Exists Between Genotypes of Sugarcane yellow leaf virus
}

\author{
Youssef Abu Ahmad, Cirad, UMR Agro.M-Cirad-Inra Biologie et Génétique des Interactions Plante-Parasite \\ (BGPI), Montpellier Cedex 5, F-34398 France; Laurent Costet, Cirad, UMR Cirad-Université de La Réunion Peu- \\ plements Végétaux et Bioagresseurs en Milieu Tropical (PVBMT), Saint-Pierre, La Réunion, F-97410 France; \\ Jean-Heinrich Daugrois, Cirad, UPR Multiplication Végétative, Petit-Bourg, Guadeloupe, F-97170 France; \\ Samuel Nibouche, Cirad, UMR Cirad-Université de La Réunion PVBMT, Saint Pierre, La Réunion, F-97410 \\ France; Philippe Letourmy, Cirad, UPR Aide à la Décision et Biostatistique, Montpellier Cedex 5, F-34398, \\ France; and Jean-Claude Girard and Philippe Rott, Cirad, UMR Agro.M-Cirad-Inra BGPI, Campus International \\ de Baillarguet, TA 41/K, Montpellier Cedex 5, F-34398 France
}

\begin{abstract}
Abu Ahmad, Y., Costet, L., Daugrois, J.-H., Nibouche, S., Letourmy, P., Girard, J.-C., and Rott, P. 2007. Variation in infection capacity and in virulence exists between genotypes of Sugarcane yellow leaf virus. Plant Dis. 91:253-259.

Two experiments, one in Guadeloupe and one in Réunion Island, were performed to transmit different genotypes of Sugarcane yellow leaf virus (SCYLV) to eight sugarcane cultivars differing in resistance to infection by the virus and to yellow leaf. Transmission was attempted from SCYLV-infected sugarcane plants or leaves to healthy tissue-cultured plantlets grown in vitro and with the aphid vector Melanaphis sacchari. After inoculation and elimination of insects with an insecticide, plantlets were transferred to Montpellier, France and grown in a greenhouse. Plants were tested for presence of SCYLV by tissue-blot immunoassay and reverse-transcription polymerase chain reaction after 5 to 6 months of growth. SCYLV genotypes BRA-PER, CUB, and REU were detected in 47,62 , and $39 \%$ of plants inoculated with these genotypes in Guadeloupe, respectively. SCYLV genotypes BRA-PER and REU and a mixed infection of genotypes BRA-PER and REU were detected in 56, 33, and $42 \%$ of plants inoculated with these genotypes in Réunion Island, respectively. Genotypes BRA-PER and CUB could be transmitted to all eight sugarcane cultivars, but genotype REU could never be transmitted to resistant sugarcane cvs. H78-4153 and H78-3567. SCYLV genotype REU was transmitted successfully to sugarcane cv. R570 in Guadeloupe, but not in Réunion Island. Genotypes BRA-PER and CUB induced yellow leaf symptoms in susceptible or highly susceptible sugarcane cultivars, whereas genotype REU induced very few symptoms. SCYLV was not found in several symptomatic plants, suggesting an association of disease with undetectable populations of the virus or a nonviral cause. This is the first report of variation in infection capacity and in virulence of SCYLV.
\end{abstract}

Additional keywords: Luteoviridae, Polerovirus

Yellow leaf of sugarcane (Saccharum spp. hybrids) is caused by Sugarcane yellow leaf virus (SCYLV) and diseased plants may exhibit intense yellowing of the leaf midrib. This discoloration of leaves often occurs while the lamina is still green. Symptoms also include shortening of terminal internodes, yellowing, and necrosis of older leaves. However, most of these symptoms may be related to other biotic or abiotic factors $(17,19)$. The disease is also associated with reduction in sucrose content in stalks, accumulation of sucrose in leaf midribs, and yield losses $(10,11,15$, $16,28,33)$. Incidence of SCYLV in com-

Corresponding author: P. Rott

E-mail: philippe.rott@ cirad.fr

Accepted for publication 19 September 2006.

DOI: 10.1094/PDIS-91-3-0253

(C) 2007 The American Phytopathological Society mercial fields can reach $100 \%$ in susceptible cultivars $(7,27,35)$, and hot-water treatment of cuttings is not effective in eliminating the virus from infected material $(6,25)$. Because infected plants are often asymptomatic, SCYLV was spread worldwide through infected germplasm before diagnostic methods were developed $(6,18,29,31)$. Resistance to SCYLV has been shown to occur in sugarcane cultivars and it appears to be the most promising means to control the disease $(31,34)$.

Sequence homology studies suggested that SCYLV arose by interspecies recombination between members of the genera Luteovirus and Polerovirus $(24,32)$. Therefore, SCYLV recently has been assigned to the genus Polerovirus of the family Luteoviridae (8). Members of Luteoviridae have ssRNA genomes, reside in the phloem tissue of plants, and are not transmitted mechanically $(13,22)$. SCYLV was transmitted successfully to healthy sugarcane plants by two aphid species that colonize sugarcane: Melanaphis sacchari and Rhopalosiphum maidis (Homoptera: Aphididae) (29,31). Transmission of members of Luteoviridae by these insects generally occurs in a persistent, circulative, and nonreplicative manner $(12,13)$.

Several genetic diversity studies showed that SCYLV was a variable virus $(1,5,23)$. Abu Ahmad and co-workers $(1,2)$ described the occurrence and geographical distribution of four SCYLV genotype groups called genotypes BRA, CUB, PER, and REU. BRA-PER, a combined genotype that represents genotypes BRA and genotype PER that are relatively close phylogenetically (1) and that could not be differentiated by specific reversetranscription polymerase chain reaction (RT-PCR) primers (2), is the most widespread. It was found in 18 different geographical locations all around the world. In contrast, genotypes CUB and REU were found in only 4 of 18 geographical locations. In most locations, plants were infected by only one of these genotypes, but in others, two or more genotypes were detected. Genotypes BRA-PER, CUB, and REU all were found in Guadeloupe in locally bred cultivars, suggesting local transmission of all three genotypes. Genotypes BRA-PER and REU were found in Réunion Island, but REU was the only one that was detected in locally bred and commercially grown cultivars.

The objective of this study was to investigate the biological significance of the occurrence of different genotypes of SCYLV, with special emphasis on infection capacity (based on transmission and infection rate) and virulence (capacity to cause leaf symptoms) of the virus. SCYLV genotypes BRA-PER, CUB, and REU in Guadeloupe and genotypes BRA-PER and REU in Réunion Island were transmitted locally via $M$. sacchari to in vitro tissuecultured plants of eight sugarcane cultivars differing in resistance to infection by SCYLV and resistance to yellow leaf. Inoculated plants then were transferred to Montpellier, France and grown in a greenhouse to analyze efficiency of transmission in a vector-free environment. Analysis of 
incidence of the different SCYLV genotypes in the eight sugarcane cultivars showed the existence of different strains within this virus species.

\section{MATERIALS AND METHODS}

Production of SCYLV-free tissuecultured sugarcane plantlets. Cuttings of eight sugarcane cultivars differing in resistance to infection by SCYLV or to yellow leaf were imported to Montpellier (Table 1). These cultivars were grown in pots in a greenhouse and meristem cultures were prepared as previously described (6). Tissue-cultured plantlets were grown and propagated at $28^{\circ} \mathrm{C}$ in 200 -by-25-mm tubes with a 12-h photoperiod, and tested for absence of SCYLV by RT-PCR after total RNA purification as described below. SCYLV-free plantlets then were transferred in sterile tubes (10 plantlets per tube) to Guadeloupe and Réunion Island for transmission experiments. Before inoculation with SCYLV, each plantlet was transferred to fresh growth medium in a single 115-by-30-mm polypropylene tube.

Inoculum sources of SCYLV genotypes. Sugarcane stalks infected by the different SCYLV genotypes and healthy control stalks were sampled in the field. Cuttings from these stalks were grown in pots in greenhouses. To avoid cross contamination, plants infected by different virus genotypes were grown in different greenhouses (Réunion Island) or in insectproof cages in the same greenhouse (Guadeloupe). Sugarcane cvs. B37-161, B86409, and R570 infected with SCYLV genotypes BRA-PER, CUB, and REU, respectively, were used as inoculum sources in Guadeloupe. Sugarcane cv. "SP71-6163" (mislabeled cultivar) (2) infected by SCYLV genotype BRA-PER or by a mixture of BRA-PER and REU, and cv. R577 infected by genotype REU, were used as inoculum sources in Réunion Island. Genotype identification was performed by RT-PCR with genotype-specific primers as described bellow. Additionally, SCYLVfree sugarcane cvs. B59-92 and R577 were used as healthy control plants in Guadeloupe and Réunion Island, respectively.

Table 1. Sugarcane cultivars used for transmission of different genotypes of Sugarcane yellow leaf virus $(\mathrm{SCYLV})^{\mathrm{v}}$

\begin{tabular}{|c|c|c|c|}
\hline Cultivar & Imported from & $\begin{array}{l}\text { Resistance level to } \\
\text { infection by SCYLV }\end{array}$ & $\begin{array}{l}\text { Resistance level to } \\
\text { yellow leaf }\end{array}$ \\
\hline CC $84-75$ & Colombia & Highly susceptible (34) & Susceptible ${ }^{y}$ \\
\hline CC85-68 & Colombia & Highly susceptible (34) & Unknown ${ }^{y}$ \\
\hline CC $85-92$ & Colombia & Resistant (34) & Unknown ${ }^{y}$ \\
\hline H50-7209 & Peru & Unknown & Highly susceptible (3) \\
\hline H78-3567 & Hawaii & Resistant (31) & Resistant (31) \\
\hline H78-4153 & Hawaii & Highly resistant (31) & Resistant (31) \\
\hline R570 & Réunion Island & Unknown & Tolerant $(27,28)$ \\
\hline SP71-6163 & Brazil & Highly susceptible ${ }^{z}$ & Highly susceptible (19) \\
\hline
\end{tabular}

${ }^{\mathrm{v}}$ References indicated in parentheses.

${ }^{\mathrm{w}}$ Based on experimental data.

${ }^{\mathrm{x}}$ Based on leaf yellowing in the field or yield data.

${ }^{y} \mathrm{~J}$. Victoria (personal communication).

z J.-H. Daugrois (unpublished results).

Sampling and rearing of $M$. sacchari. The SCYLV aphid vector $M$. sacchari was collected in Guadeloupe and Réunion Island from sugarcane plants that tested negative for SCYLV by tissue-blot immunoassay (TBIA). In order to obtain virusfree aphids, $M$. sacchari individuals were reared on healthy sugarcane leaves of cv. B59-92 in Guadeloupe and cv. R577 in Réunion Island. Rearing was performed with 2- to 4-month-old plants grown in pots and covered with insect-proof cages in Guadeloupe, whereas rearing was performed in glass tubes on detached leaf fragments in Réunion Island (Fig. 1). In Réunion Island, approximately 25 -cm-long leaf pieces were taken from the youngest fully emerged leaf of 2- to 4-month-old sugarcane plants grown in a greenhouse, and surface disinfested with an ethanolsoaked cloth under a laminar flow hood. Each leaf fragment was then gently folded, and the two extremities of the U-shaped leaf fragment were inserted in a 200-by$25-\mathrm{mm}$ glass tube containing $20 \mathrm{ml}$ of agar medium (15 $\mathrm{g}$ of agar, propiconazole at 25 ppm, and 1 liter of distilled water). Tubes were maintained on the bench in the laboratory at $24^{\circ} \mathrm{C}$ for 2 to 3 weeks with a $12-\mathrm{h}$ photoperiod. In both locations, newly born individuals from adult aphids were sampled and reared on new plants or detached leaves, and this procedure was performed for at least two consecutive aphid generations. To produce viruliferous aphids, virus-free stage-four nymphs or adult aphids were reared for 3 to 5 weeks on entire virus-infected plants in a greenhouse in Guadeloupe, and for at least two consecutive generations in the laboratory on detached virus-infected sugarcane leaves in Réunion Island.

Aphid transmission assays. Viruliferous stage-one to -four nymphs of $M$. sacchari were taken from SCYLV-infected leaves and transferred one by one to SCYLV-free tissue-cultured sugarcane plantlets using a paint brush. In each geographical location, 10 to 13 plantlets were inoculated per sugarcane cultivar and per SCYLV genotype, and 7 to 10 nymphs were deposited on the emerging leaves of

254 Plant Disease / Vol. 91 No. 3 each plantlet (Fig. 2). The same procedure was used with control plants, but nymphs of $M$. sacchari were taken from SCYLVfree leaves. The nymphs were allowed to feed on the plantlets for a 48- to 72-h inoculation access period (IAP). Plantlets then were sprayed in the polypropylene tube with an insecticide (imidacloprid at 100 ppm). Within 1 week after the transmission assays, inoculated sugarcane plantlets were transferred to Montpellier and to a growth chamber. Plantlets were grown for 1 month in 7-by-7-by-6.5-cm pots containing peat moss and compost $(1: 1, \mathrm{vol} / \mathrm{vol})$, and then transferred to a quarantine glasshouse in 11-by-11-by-12$\mathrm{cm}$ pots containing the same culture medium. After 1 month of growth in the quarantine glasshouse, plants were transferred to 5-liter pots containing a mixture of peat moss, compost, and volcanic rock $(2: 2: 1$, $\mathrm{vol} / \mathrm{vol} / \mathrm{vol}$ ) and grown in a regular greenhouse for another 4 months. Plants were observed for symptom development (yellowing of the leaf midrib and yellowing and necrosis of the leaf blade) every 2 weeks, and tested for SCYLV by TBIA and RT-PCR without RNA purification 5 to 6 months after inoculation as described below. The aphid transmission experiment was performed first in Guadeloupe, and the second experiment was performed in Réunion Island 3 weeks later.

Experimental design in the greenhouse in Montpellier. Plants inoculated with SCYLV in Guadeloupe and in Réunion Island were grown separately in two adjacent greenhouses. In each greenhouse, plants of each cultivar-SCYLV genotype combination were divided arbitrarily into two groups and each group was distributed in one of two adjacent blocks.

Detection of SCYLV in sugarcane by TBIA. TBIA with the youngest fully emerged leaf was performed as described by Schenck et al. (30), except that Fast Blue BB salt (Sigma) was used. Membranes were analyzed with a stereomicroscope $(\times 100)$ to determine positive reactions.

Detection of SCYLV in sugarcane by RT-PCR with RNA purification. Total RNA from the youngest fully emerged leaf was extracted and purified from sugarcane leaves (100 mg of lamina and midrib) with the RNeasy Plant Mini Kit (Qiagen) using the manufacturer's protocol. Total RNA was eluted in a final volume of $40 \mu \mathrm{l}$ of diethylpyrocarbonate (DEPC)-treated water and stored at $-20^{\circ} \mathrm{C}$. RT-PCR was performed using the Ready-To-Go RT-PCR Beads (Amersham Biosciences): $46 \mu \mathrm{l}$ of DEPC water, $1 \mu$ of each primer YLS111 and YLS462 $(10 \mu \mathrm{M})(1)$, and $2 \mu \mathrm{l}$ of eluted RNA were added to each reaction tube. The RT-PCR program was $45^{\circ} \mathrm{C}$ for $45 \mathrm{~min} ; 95^{\circ} \mathrm{C}$ for $2 \mathrm{~min} ; 35$ cycles of $95^{\circ} \mathrm{C}$ for $1 \mathrm{~min}, 60^{\circ} \mathrm{C}$ for $1 \mathrm{~min}$, and $72^{\circ} \mathrm{C}$ for 1 min; and a final $72^{\circ} \mathrm{C}$ extension step for 10 min. The amplified fragment from the coat 
protein coding sequence had an expected size of $351 \mathrm{bp}$. This detection method was applied to all plants that were further used for SCYLV genotype identification.

Detection of SCYLV in sugarcane by RT-PCR without RNA purification. Total RNA was extracted from the midrib of the youngest fully emerged leaf of sugarcane plants. Each midrib fragment $(50 \mathrm{mg})$ was deposited in a 2-ml tube containing two steel pellets ( $3 \mathrm{~mm}$ in diameter). The sample was frozen by immersion of the tube for $30 \mathrm{~s}$ in liquid nitrogen, and then homogenized with the Retsch MM301 extractor (Fisher Bioblock Scientific) three times for $30 \mathrm{~s}$ each. Carbonate coating buffer $(500 \mu \mathrm{l} ; 2 \%$ [wt/vol] PVP-40 and $1 \%$ [wt/vol] $\mathrm{Na}_{2} \mathrm{SO}_{3}$ ) was added to each tube, which was centrifuged at $8,800 \mathrm{rpm}$ for $5 \mathrm{~min}$, and the supernatant was stored at $4^{\circ} \mathrm{C}$. For RT-PCR assay, $25 \mu \mathrm{l}$ of extracted RNA was incubated overnight at $4^{\circ} \mathrm{C}$ in $200-\mu l$ microcentrifuge tubes. These tubes were washed two times with phosphate-buffered saline (PBS)-Tween 20 and once with DEPC water. RT-PCR was performed using the Titan One Tube RT-PCR System kit (Roche). The 25- $\mu$ l RT-PCR mix consisted of $5 \mu$ l of RT-PCR buffer (5x), $1.25 \mu \mathrm{l}$ of dithiothreitol solution (100

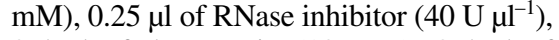
$0.5 \mu \mathrm{l}$ of dNTP mix $(10 \mathrm{mM}), 0.5 \mu \mathrm{l}$ of Titan enzyme mix, $0.1 \mu \mathrm{l}$ of each primer YLS111 and YLS462 (100 $\mu \mathrm{M})(1)$, and
DEPC water to final volume. The RT-PCR program was $54^{\circ} \mathrm{C}$ for $60 \mathrm{~min} ; 94^{\circ} \mathrm{C}$ for 2 min; 30 cycles of $94^{\circ} \mathrm{C}$ for $15 \mathrm{~s}, 61^{\circ} \mathrm{C}$ for 2 min, and $68^{\circ} \mathrm{C}$ for $2 \mathrm{~min}$; and a final $68^{\circ} \mathrm{C}$ extension step for $10 \mathrm{~min}$. This RT-PCR method was applied to detect SCYLV in all inoculated plants grown in the greenhouse in Montpellier that tested negative by TBIA.

Detection of SCYLV in aphids. Total RNA of three to five pooled aphids was extracted and purified with the RNeasy Plant Mini Kit (Qiagen) using the manufacturer's protocol. Total RNA was eluted in a final volume of $40 \mu \mathrm{l}$ of DEPC water and stored at $-20^{\circ} \mathrm{C}$. RT-PCR with diagnostic primers YLS111 and YLS462 was performed using the Ready-To-Go RTPCR Beads (Amersham Biosciences) as described above.

SCYLV genotype identification. SCYLV genotypes were identified by RTPCR using specific primers as described by Abu Ahmad et al. (2). The genotype was determined in each plant used as inoculum source. Two samples of three to five aphids per inoculum source were used to identify the SCYLV genotypes in insects reared on entire plants or detached leaves. At least two infected plants from each sugarcane cultivar-inoculum combination were used in each transmission trial, except when infected plants were not available.

Statistical analyses. The logit $\{\log$ $[p /(1-p)]\}$ of the infection probability $p$ was analyzed for the sugarcane cultivars and the SCYLV genotypes. The generalized linear model was used (21), and the number $x_{i j}$ of infected plants of sugarcane cultivar $i$ and virus genotype $j$ was distributed as a binomial $B\left(n_{i j} ; p_{i j}\right)$. The logit of $p_{i j}$ expectation was written as the linear model $\log \left\{p_{i j} /\left[1-p_{i j}\right]\right\}=\mu+\alpha_{i}+\beta_{j}$, where $\alpha_{i}$ was the effect of sugarcane cultivar $i$ and $\beta_{j}$ the effect of SCYLV genotype $j$. The generalized linear model was performed with Genmod procedure of SAS software (release 8.2; SAS Institute Inc., Cary, NC). Quality of adjustment was tested with Pearson's $\chi^{2}$ test to evaluate the need of an overdispersion parameter ( $\phi$ adjusted on Pearson's $\chi^{2}$ statistic) in comparison with the binomial distribution. This overdispersion also could be considered as a cultivargenotype interaction. The sugarcane cultivar and virus genotype effects were tested by the $\chi^{2}$ test when the model was a good fit. These two effects were tested by the Fisher-Snedecor $(F)$ test when a multiplicative overdispersion was found, and incidences of virus genotypes then were compared for each sugarcane cultivar with Fisher's exact test.

The logit model could not be applied to symptomatic plant data because the number of symptomatic plants was low or nil for several sugarcane cultivars and for SCYLV genotype REU. For this reason, the symptomatic plant data were analyzed

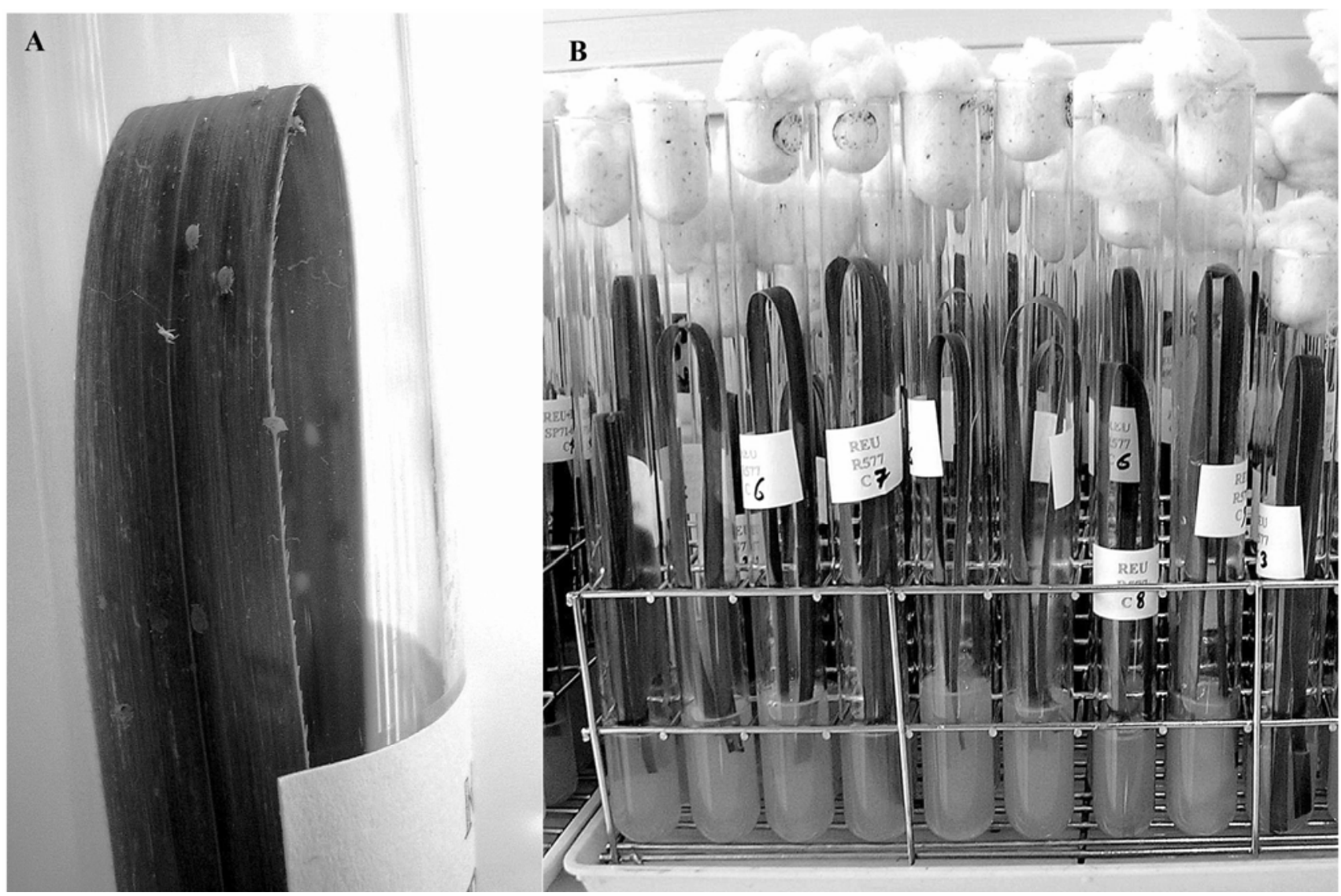

Fig. 1. Rearing of the aphid Melanaphis sacchari on detached sugarcane leaves. A, Nymphs of M. sacchari on a sugarcane leaf fragment. B, U-shaped sugarcane leaf fragments in glass tubes. 
with Fisher's exact test using the proc Freq procedure of SAS software (release 8.2; SAS Institute Inc.). Cumulated average numbers of symptomatic plants were analyzed separately for the sugarcane cultivars and the SCYLV genotypes. Pairwise comparisons of sugarcane cultivars and of SCYLV genotypes also were performed with Fisher's exact test.

\section{RESULTS}

Presence of SCYLV in sugarcane plants and aphids used for transmission of the virus. SCYLV was detected and the virus genotype determined in all plants used for M. sacchari rearing (Tables 2 to $5)$. The virus also was found by RT-PCR in the 12 pooled aphid samples that were taken arbitrarily among the reared insect populations. The genotypes of SCYLV

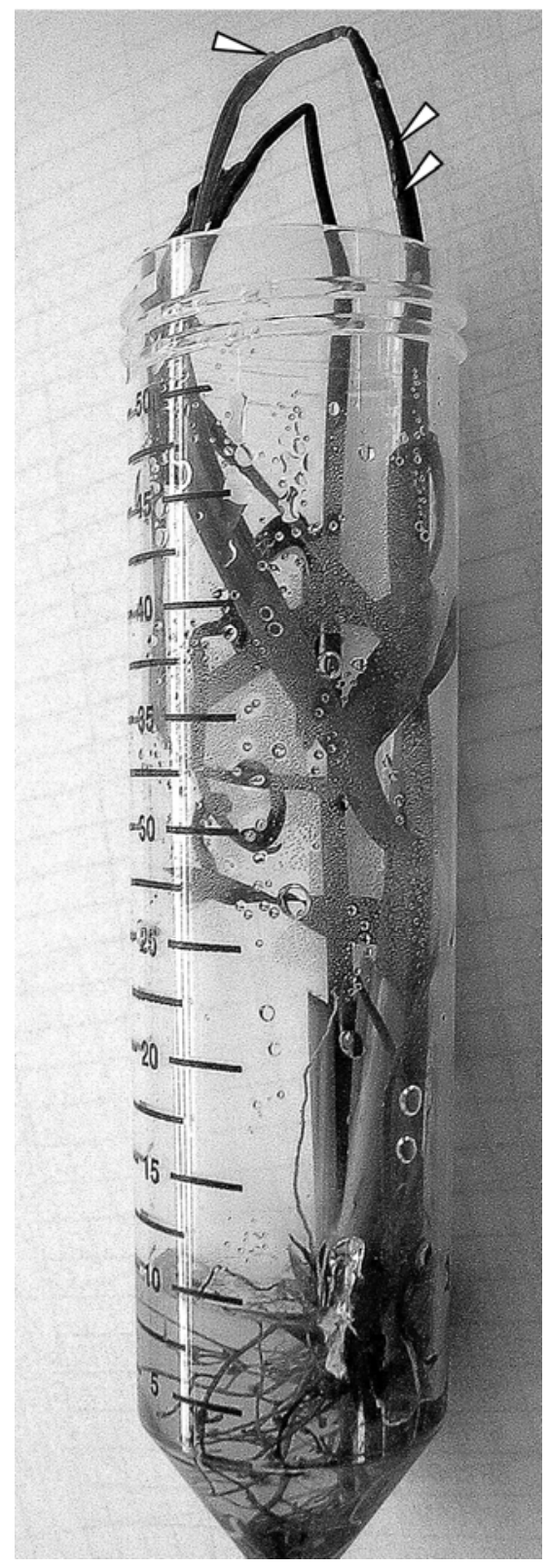

Fig. 2. Tissue-cultured plantlet inoculated with Sugarcane yellow leaf virus. Arrows indicate nymphs of Melanaphis sacchari. present in these aphids were identical to the virus genotypes present in the plants on which the aphids were reared. The virus was not detected in the healthy control plants and in the aphids reared on these plants.

SCYLV transmission efficiency. In all, 10 to 13 tissue-cultured plantlets were inoculated for each sugarcane cultivarSCYLV genotype combination in Guadeloupe and in Réunion Island (with the exception of control plants of cvs. CC8475, CC85-68, CC85-92, and H78-3567 that were not available in Réunion Island). Because some plantlets failed to grow after transfer from the glass tube to the greenhouse, the final number of inoculated plants varied from 2 to 13 (Tables 2 to 5). SCYLV was detected by TBIA in $86(39 \%)$ of 218 plants inoculated in Guadeloupe 5 and 6 months after plant inoculation. Additionally, 20 TBIA-negative plants tested positive by RT-PCR 6 months after inoculation, and 106 (49\%) of 218 plants were found infected by the virus. SCYLV was detected by TBIA in $39(22 \%)$ and 41 (23\%) of 175 plants inoculated in Réunion Island 5 and 6 months after plant inoculation, respectively. Additionally, 35 TBIAnegative plants tested positive by RT-PCR 6 months after inoculation, and $76(43 \%)$ of 175 plants were found to be infected by the virus.

Infection data 6 months after inoculation were analyzed statistically. No data correction was needed to take into account a sugarcane cultivar-virus genotype interaction for the transmission trial performed in Guadeloupe (overdispersion parameter $\phi=$ $1.15, P=0.3105)$, and the cultivar and genotype effects were significant at $P<$ 0.0001 and $P=0.0077$, respectively (Table 2). In contrast, an overdispersion parameter was needed for the transmission trial performed in Réunion Island $(\phi=3.33, P$ $<0.0001$ ), and no significant sugarcane cultivar or SCYLV genotype effect was found $(P=0.2866$ and 0.3042 , respectively). The overdispersion of these latter data compared with a binomial distribution of infected plants was attributed to a sugarcane cultivar-virus genotype interaction in this trial, and this interaction was evident for several cultivars, especially for H78-4153 and R570 (Table 3).

In Guadeloupe, the transmission rate of SCYLV genotype CUB (62\% of infected plants) was higher than transmission rates of genotypes BRA-PER (47\%) and REU (39\%) that were not significantly different (Table 2). In Réunion Island, transmission rates of genotypes BRA-PER (56\%) and REU (33\%) were not significantly different either; however, this result may have been biased by the overdispersion of data (Table 3 ). The transmission rate of genotype mixture BRA-PER + REU (42\%) was not different from the transmission rates of genotypes BRA-PER and REU transmitted separately.

Variation in SCYLV infection capacity. SCYLV genotype BRA-PER was de- tected in at least 2 of 10 inoculated plants of all eight sugarcane cultivars in Guadeloupe and Réunion Island. Similarly, genotype CUB was found in at least 3 of 10 inoculated plants of all eight sugarcane cultivars in Guadeloupe. None of the 40 plants of highly resistant sugarcane cvs. H78-3567 and H78-4153 inoculated with genotype REU in Guadeloupe and in Réunion Island was infected by this genotype 6 months after plant inoculation (Tables 2 and 3). In contrast, 13 of 32 plants of these two cultivars were infected by genotype BRA-PER.

SCYLV genotype REU was detected in six of nine plants of sugarcane cv. R570 inoculated with this genotype in Guadeloupe (Table 2), whereas it was not found in any of the nine plants of sugarcane cv. R570 inoculated with genotype REU in Réunion Island (Table 3). Additionally, the five plants of cv. R570 infected by SCYLV after inoculation with the mixture of genotypes BRA-PER + REU all were infected by genotype BRA-PER only. Similarly, only genotype BRA-PER was detected in the SCYLV-positive plant of cv. H78-4153 inoculated with this genotype mixture. Genotypes BRA-PER and REU were detected in the SCYLV-infected plants of all the other sugarcane cultivars.

Variation in SCYLV virulence based on disease symptoms. Symptoms of leaf yellowing were observed first in the greenhouse 3 months after inoculation of plants with SCYLV. At the end of the experiments (6 months after plant inoculation), $31(14 \%)$ of 218 plants inoculated in Guadeloupe and 29 (17\%) of 175 plants inoculated in Réunion Island exhibited disease symptoms (Tables 4 and 5). Genotypes BRA-PER, CUB, and REU incited symptoms in 11 of $73(15 \%), 17$ of $68(25 \%)$, and 3 of 77 (4\%) plants inoculated in Guadeloupe, respectively. Genotype BRAPER, the mixture of genotype BRA-PER and REU, and genotype REU incited symptoms in 14 of 57 (25\%), 15 of 55 (27\%), and 0 of $63(0 \%)$ plants inoculated in Réunion Island, respectively. Highly significant sugarcane cultivar $(P<0.0001)$ and SCYLV genotype $(P<0.0015)$ effects were found in both experiments, and the percentage of symptomatic plants inoculated with genotype BRA-PER was higher than the percentage of symptomatic plants inoculated with genotype REU (Tables 4 and 5). None of the 103 control plants exhibited yellow leaf symptoms. Four plants of highly susceptible sugarcane cvs. H50-7209 and SP71-6163, inoculated with SCYLV genotype BRA-PER in Guadeloupe, showed disease symptoms (Table 4), although the virus was not detected in these plants (Table 2). Similarly, one plant of susceptible cv. CC84-75 inoculated with genotype BRA-PER, and three plants of highly susceptible cv. H50-7209 inoculated with mixed genotypes BRA-PER and REU in Réunion Island, showed yellow leaf 
symptoms (Table 5), although the virus was not detected in these plants (Table 3 ).

No plant of highly resistant cvs. H783567 and H78-4153 and tolerant cv. R570 exhibited disease symptoms, whatever the SCYLV genotype and the geographical location where the plants were inoculated. Genotype BRA-PER from Guadeloupe incited symptoms in highly susceptible sugarcane cvs. H50-7209 and SP71-6163 (Table 4). Genotype BRA-PER from Réunion Island, alone or in mixture with genotype REU, incited symptoms in the same cultivars and in three additional cultivars (Table 5).

Variation in sugarcane resistance to infection by SCYLV. The percentage of plants infected by SCYLV varied between 22\% (resistant cv. H78-3567 and highly resistant cv. H78-4153) and 68\% (highly susceptible cvs. CC84-75 and SP71-6163) in the transmission experiment performed in Guadeloupe (Table 2), and between $10 \%$ (resistant cv. H78-3567) and 71\% (highly susceptible cv. CC85-68) in the transmission experiment performed in Réunion Island (Table 3). The percentages of in- fected plants of resistant cv. H78-3567 and highly resistant cv. H78-4153 were different from the percentages of infected plants of cvs. CC84-75 (highly susceptible), CC85-68 (highly susceptible), CC85-92 (resistant), R570 (unknown resistance to infection), and SP71-6163 (highly susceptible), but not from cv. H50-7209 (resistance to infection unknown but highly susceptible to yellow leaf) in the transmission experiment performed in Guadeloupe (Table 2). No significant differences of infection percentages were found between sugarcane cultivars in the transmission experiment performed in Réunion Island (Table 3); however, this result may have been biased by the overdispersion of data and existence of a sugarcane cultivarSCYLV genotype interaction in this trial (Table 3). In this experiment, as shown above, plants of sugarcane cvs. H78-3567, $\mathrm{H} 78-4153$, and R570 were infected by SCYLV genotype BRA-PER but not by genotype REU.

Variation in sugarcane resistance to yellow leaf. The percentage of plants showing disease symptoms varied between
0\% (sugarcane cv. CC85-92, whose resistance to yellow leaf is unknown; resistant sugarcane cvs. H78-3567 and H78-4153; and tolerant cv. R570) and 52\% (highly susceptible cv. SP71-6163) in the transmission experiment performed in Guadeloupe (Table 4), and between 0\% (resistant sugarcane cvs. H78-3567 and H78-4153 and tolerant cv. R570) and 62\% (highly susceptible cv. H50-7209) in the transmission experiment performed in Réunion Island (Table 5).

\section{DISCUSSION}

In this study, two different rearing methods and an unusual plant inoculation method were used successfully to transmit SCYLV from diseased to healthy sugarcane plants. Rearing M. sacchari aphids on infected sugarcane plants has been described and used for SCYLV transmission by several authors $(18,29,31)$, but this is the first report of rearing $M$. sacchari on detached sugarcane leaves in the laboratory. Additionally, in vitro inoculation of tissue-cultured sugarcane plantlets allowed us to inoculate eight sugarcane cultivars

Table 2. Incidence of three Sugarcane yellow leaf virus (SCYLV) genotypes after transmission to eight sugarcane cultivars in Guadeloupe

\begin{tabular}{|c|c|c|c|c|c|}
\hline \multirow[b]{2}{*}{ Cultivar $(\text { resistance })^{\mathrm{y}}$} & \multicolumn{4}{|c|}{ SCYLV genotype (sugarcane host cultivar) ${ }^{\mathrm{x}}$} & \multirow[b]{2}{*}{ Total no. $(\%)^{z}$} \\
\hline & Control (B59-92) & BRA-PER (B37-161) & CUB (B86-409) & REU (R570) & \\
\hline CC84-75 (HS) & $0 / 8$ & $7 / 10$ & $6 / 7$ & $4 / 8$ & $17 / 25(68)$ a \\
\hline CC85-68 (HS) & $0 / 9$ & $5 / 9$ & $7 / 10$ & $5 / 10$ & $17 / 29$ (59) a \\
\hline CC85-92 (R) & $0 / 10$ & $4 / 7$ & $5 / 10$ & $4 / 10$ & $13 / 27$ (48) a \\
\hline H50-7209 (unknown) & $0 / 10$ & $3 / 10$ & $5 / 8$ & $4 / 8$ & $12 / 26(46) a, b$ \\
\hline H78-3567 (R) & $0 / 9$ & $2 / 10$ & $4 / 9$ & $0 / 9$ & $6 / 28(22) b$ \\
\hline H78-4153 (HR) & $0 / 7$ & $4 / 9$ & $3 / 10$ & $0 / 13$ & $7 / 32(22) b$ \\
\hline R570 (unknown) & $0 / 4$ & $5 / 9$ & $6 / 8$ & $6 / 9$ & $17 / 26(65)$ a \\
\hline SP71-6163 (HS) & $0 / 11$ & $4 / 9$ & $6 / 6$ & $7 / 10$ & $17 / 25(68)$ a \\
\hline Total no. $(\%)^{\mathrm{z}}$ & $0 / 68(0)$ & $34 / 73 \mathrm{~b}(47)$ & $42 / 68$ a (62) & 30/77 b (39) & $\ldots$ \\
\hline
\end{tabular}

$\mathrm{x}$ Number of SCYLV infected plants/total number of inoculated plants; infected plants reacted positively by tissue-blot immunoassay or reverse-transcription polymerase chain reaction 6 months after plant inoculation.

y Sugarcane cultivar (resistance level to infection by SCYLV). HS = highly susceptible, $\mathrm{R}=$ resistant, and HR $=$ highly resistant.

${ }^{\mathrm{z}}$ Values followed by the same letter are not significantly different at $P=0.05$ according to the $\chi^{2}$ pairwise test (data of control plants were not included in the statistical analysis).

Table 3. Incidence of two Sugarcane yellow leaf virus (SCYLV) genotypes after transmission to eight sugarcane cultivars in Réunion Island

\begin{tabular}{|c|c|c|c|c|c|c|}
\hline \multirow[b]{2}{*}{ Cultivar $\left(\right.$ resistance) ${ }^{\mathrm{v}}$} & \multicolumn{4}{|c|}{ SCYLV genotype (sugarcane host cultivar) ${ }^{u}$} & \multirow[b]{2}{*}{ Total no. $(\%)^{x}$} & \multirow[b]{2}{*}{$P$ value ${ }^{y}$} \\
\hline & $\begin{array}{l}\text { Control } \\
\text { (R577) }\end{array}$ & $\begin{array}{c}\text { BRA-PER } \\
\text { ("SP71-6163")" }\end{array}$ & $\begin{array}{c}\text { BRA-PER + REU } \\
(\text { ("SP71-6163”)w }\end{array}$ & $\begin{array}{c}\text { REU } \\
\text { (R577) }\end{array}$ & & \\
\hline CC84-75 (HS) & $\ldots$ & $2 / 10$ & $\ldots$ & $2 / 4$ & $4 / 14(29)$ & 0.5205 \\
\hline CC85-68 (HS) & $\ldots$ & $5 / 10$ & $10 / 10$ & $7 / 11$ & $22 / 31(71)$ & 0.0308 \\
\hline CC85-92 (R) & & $7 / 10$ & $2 / 10$ & $7 / 9$ & $16 / 29(55)$ & 0.0323 \\
\hline H50-7209 (unknown) & $0 / 8$ & $2 / 2$ & $3 / 6$ & $3 / 5$ & $8 / 13(62)$ & 0.7669 \\
\hline $\mathrm{H} 78-3567(\mathrm{R})$ & $\ldots$ & $2 / 5$ & $0 / 7$ & $0 / 9$ & $2 / 21(10)$ & 0.0476 \\
\hline H78-4153 (HR) & $0 / 10$ & $5 / 8$ & $1^{z} / 9$ & $0 / 8$ & $6 / 25(24)$ & 0.0115 \\
\hline R570 (unknown) & $0 / 8$ & $3 / 3$ & $5^{z} / 8$ & $0 / 9$ & $8 / 20(40)$ & 0.0007 \\
\hline SP71-6163 (HS) & $0 / 9$ & $6 / 9$ & $2 / 5$ & $2 / 8$ & $10 / 22(45)$ & 0.3044 \\
\hline Total no. $(\%)^{\mathrm{y}}$ & $0 / 35(0)$ & $32 / 57(56)$ & $23 / 55(42)$ & $21 / 63(33)$ & $\ldots$ & $\ldots$ \\
\hline
\end{tabular}

u Number of SCYLV infected plants/total number of inoculated plants; infected plants reacted positively by tissue-blot immunoassay or reverse-transcription polymerase chain reaction 6 months after plant inoculation.

${ }^{v}$ Sugarcane cultivar (resistance level to infection by SCYLV). HS = highly susceptible, $\mathrm{R}=$ resistant, and HR = highly resistant.

${ }^{\mathrm{w}}$ Mislabeled sugarcane cultivar (2).

${ }^{\mathrm{x}}$ Total (\%) except control.

${ }^{y}$ No overall significant differences were found between sugarcane cultivars and SCYLV genotypes according to the Fisher Snedecor $(\mathrm{F})$ test at $P=0.05$ (data of control plants were not included in the statistical analysis). However, significant sugarcane cultivar x virus genotype interaction was found with the over-dispersion test, and virus effect for each cultivar was determined by the $P$ value of Fisher's exact test.

${ }^{z}$ Plants infected by SCYLV genotype BRA-PER only; infected plants of all other sugarcane cultivars inoculated with genotype mixture BRA-PER + REU were infected by the two genotypes. 
with different SCYLV isolates in two geographical locations (Guadeloupe and Réunion Island), and to study inoculated plants in a single environment (Montpellier) with almost no risk of subsequent cross-contamination between plants. Indeed, M. sacchari does not exist in mainland France and the only putative vector of SCYLV existing on maize in the South of France, $R$. maidis, does not colonize sugarcane in our local conditions (G. Labonne, unpublished results).

Several differences observed between SCYLV isolates or genotypes suggested variation in infection capacity and virulence of this virus. Percentage of infected and symptomatic plants inoculated with SCYLV genotype CUB was higher than the percentage of infected plants inoculated by genotypes BRA-PER or REU. This difference must, however, be confirmed by additional experiments in Guadeloupe because genotype CUB has not been found in Réunion Island (2). No difference in overall transmission rate was found by statistical analysis between SCYLV genotypes BRA-PER and REU in the experiments performed in Guadeloupe and in Réunion Island. However, variation in infection capacity and virulence based on sugarcane infection and disease symptom development, respectively, was observed between these two genotypes.
Whereas sugarcane cvs. H78-3567 and H78-4153 were successfully inoculated with SCYLV genotype BRA-PER in Guadeloupe and in Réunion Island, the virus was never detected in plants of these two cultivars inoculated with genotype REU. This sugarcane cultivar-SCYLV genotype interaction is proof that genotypes BRAPER and REU are two strains of SCYLV.

Additionally, infection capacity of genotype REU varied according to the geographical origin of the members of this virus group. Genotype REU was transmitted successfully to sugarcane cv. R570 in Guadeloupe, but transmission failed in Réunion Island with two different inoculum sources of the pathogen: genotype REU was not detected in plants of cv. R570 inoculated in Réunion Island with this genotype alone or with a mixture of genotypes BRA-PER and REU. The failure of transmission of SCYLV genotype REU to sugarcane cv. R570 in Réunion Island may explain why incidence of the virus did not significantly vary in a recent 3 year survey of several R570 fields in this geographical location (27). Similar results were obtained recently in Colombia, where an SCYLV isolate was transmitted successfully via $M$. sacchari to several sugarcane cultivars, except to healthy plants of the sugarcane cultivar from which it originated (J. Victoria, personal communication).
The failure of transmission of SCYLV genotype REU to sugarcane cv. R570 suggests that this virus genotype evolved in Réunion Island during the last decades because sugarcane cv. R570 was created in 1964 by CERF in Réunion Island and plants of R570 infected by SCYLV genotype REU exist in this geographical location. Further investigations will be necessary to identify the genetic origin of this pathogenic variation in SCYLV genotype REU.

The number of symptomatic plants was not related to plant infection, and 122 of 182 plants infected by SCYLV did not exhibit disease symptoms, thus confirming previous field observations $(16,29,33)$. However, differences in number of symptomatic plants confirmed conclusions based on infection data. Genotype REU caused almost no symptoms in the plants inoculated with this genotype in Guadeloupe and Réunion Island, whereas 15 to $25 \%$ of plants inoculated with genotype BRA-PER were symptomatic. Therefore, SCYLV genotype BRA-PER is a more aggressive strain than genotype REU. Pathogenicity variation within genotype BRA-PER also may exist because this genotype from Réunion Island caused symptoms in more cultivars than the same genotype from Guadeloupe. These results, however, must be confirmed by additional or repeated data. Additionally, SCYLV was

Table 4. Number of symptomatic plants of eight sugarcane cultivars inoculated with three Sugarcane yellow leaf virus (SCYLV) genotypes in Guadeloupe

\begin{tabular}{|c|c|c|c|c|c|}
\hline \multirow[b]{2}{*}{ Cultivar (resistance) ${ }^{\mathrm{y}}$} & \multicolumn{4}{|c|}{ SCYLV genotype (sugarcane host cultivar) } & \multirow[b]{2}{*}{ Total no. $(\%)^{\mathrm{z}}$} \\
\hline & Control (B59-92) & BRA-PER (B37-161) & CUB (B86-409) & REU (R570) & \\
\hline CC84-75 (S) & $0 / 8$ & $0 / 10$ & $4 / 7$ & $0 / 8$ & $4 / 25(16) b$ \\
\hline CC85-68 (unknown) & $0 / 9$ & $0 / 9$ & $3 / 10$ & $0 / 10$ & $3 / 29(10) b, c$ \\
\hline CC85-92 (unknown) & $0 / 10$ & $0 / 7$ & $0 / 10$ & $0 / 10$ & $0 / 27(0) \mathrm{c}$ \\
\hline H50-7209 (HS) & $0 / 10$ & $5 / 10$ & $5 / 8$ & $1 / 8$ & $11 / 26(42)$ a \\
\hline $\mathrm{H} 78-3567(\mathrm{R})$ & $0 / 9$ & $0 / 10$ & $0 / 9$ & $0 / 9$ & $0 / 28(0) \mathrm{c}$ \\
\hline $\mathrm{H} 78-4153(\mathrm{R})$ & $0 / 7$ & $0 / 9$ & $0 / 10$ & $0 / 13$ & $0 / 32(0) \mathrm{c}$ \\
\hline R570 (T) & $0 / 4$ & $0 / 9$ & $0 / 8$ & $0 / 9$ & $0 / 26(0) b, c$ \\
\hline SP71-6163 (HS) & $0 / 11$ & $6 / 9$ & $5 / 6$ & $2 / 10$ & $13 / 25(52) \mathrm{a}$ \\
\hline Total no. $(\%)^{\mathrm{z}}$ & $0 / 68(0)$ & $11 / 73$ a (15) & $17 / 68$ a (25) & $3 / 77$ b (4) & $\ldots$ \\
\hline
\end{tabular}

${ }^{x}$ Number of plants with yellow leaf symptoms/total number of inoculated plants.

${ }^{y}$ Sugarcane cultivar (resistance level to yellow leaf). $\mathrm{HS}=$ highly susceptible, $\mathrm{S}=$ susceptible, $\mathrm{T}=$ tolerant, and $\mathrm{R}=$ resistant.

${ }^{\mathrm{z}}$ Values followed by the same letter are not significantly different at $P=0.05$ according to Fisher's exact test (data of control plants were not included in the statistical analysis).

Table 5. Number of symptomatic plants of eight sugarcane cultivars inoculated with two Sugarcane yellow leaf virus genotypes in Réunion Island

\begin{tabular}{|c|c|c|c|c|c|}
\hline \multirow[b]{2}{*}{ Cultivar $\left(\right.$ resistance) ${ }^{\mathrm{w}}$} & \multicolumn{4}{|c|}{ SCYLV genotype (sugarcane host cultivar) ${ }^{\mathrm{v}}$} & \multirow[b]{2}{*}{ Total no. $(\%)^{\mathrm{y}}$} \\
\hline & Control (R577) & BRA-PER (“SP71-6163”)x' & BRA-PER + REU (“SP71-6163”) ${ }^{x}$ & REU (R577) & \\
\hline CC84-75 (S) & $\ldots$ & $3 / 10$ & $\ldots$ & $0 / 4$ & $3 / 14$ (21) a,b,c \\
\hline CC85-68 (unknown) & $\ldots$ & $4 / 10$ & $6 / 10$ & $0 / 11$ & $10 / 31(32) \mathrm{a}$ \\
\hline CC85-92 (unknown) & & $1 / 10$ & $1 / 10$ & $0 / 9$ & $2 / 29(7) b, c$ \\
\hline H50-7209 (HS) & $0 / 8$ & $2 / 2$ & $6 / 6$ & $0 / 5$ & $8 / 13(62) a$ \\
\hline H78-3567 (R) & & $0 / 5$ & $0 / 7$ & $0 / 9$ & $0 / 21(0) \mathrm{c}$ \\
\hline H78-4153 (R) & $0 / 10$ & $0 / 8$ & $0 / 9^{z}$ & $0 / 8$ & $0 / 25(0) c$ \\
\hline R570 (T) & $0 / 8$ & $0 / 3$ & $0 / 8^{z}$ & $0 / 9$ & $0 / 20(0) \mathrm{c}$ \\
\hline SP71-6163 (HS) & $0 / 9$ & $4 / 9$ & $2 / 5$ & $0 / 8$ & $6 / 22(27) a, b$ \\
\hline Total no. $(\%)^{\mathrm{y}}$ & $0 / 35(0)$ & $14 / 57$ a (25) & $15 / 55$ a (27) & $0 / 63 \mathrm{~b}(0)$ & $\ldots$ \\
\hline
\end{tabular}

${ }^{\mathrm{v}}$ Number of plants with yellow leaf symptoms/total number of inoculated plants.

${ }^{\text {w }}$ Sugarcane cultivar (resistance level to yellow leaf). $\mathrm{HS}=$ highly susceptible, $\mathrm{S}=$ susceptible, $\mathrm{T}=$ tolerant, and $\mathrm{R}=$ resistant.

${ }^{\mathrm{x}}$ Mislabeled sugarcane cultivar (2).

${ }^{y}$ Values followed by the same letter are not significantly different at $P=0.05$ according to Fisher's exact test (data of control plants were not included in the statistical analysis).

${ }^{\text {z }}$ Plants infected by SCYLV genotype BRA-PER only. 
not detected in several plants showing yellow leaf symptoms but inoculated with SCYLV genotype BRA-PER. Therefore, these symptoms were caused by virus populations of this genotype not detected by TBIA and RT-PCR, or by an undetermined physiological disorder.

In Hawaii, sugarcane cv. H78-4153 is highly resistant to infection by SCYLV (31). In this geographical location, cv. H78-4153 remained virus-free in SCYLVcontaminated fields over a 1-year period of observation, and all aphid-inoculated plants tested negative for SCYLV (31). In contrast, in this study, H78-4153 was infected by genotype BRA-PER in Réunion Island and in Guadeloupe, and also by genotype CUB in Guadeloupe. These differences in transmission efficiency may be additional evidence for variation in infection capacity of SCYLV or may be caused by variation in biotypes of $M$. sacchari in the different geographical locations. Virus transmission is correlated with host and environment adaptation in several aphid species $(4,13,14,26)$. Additionally, several field populations or clones of $M$. sacchari differing in their ability to transmit SCYLV may exist, as was shown for the aphids $R$. padi and Sitobion avenae and transmission of different Barley yellow $d$ warf virus serotypes $(9,20)$.

This study is the first report of a rearing method of $M$. sacchari on detached sugarcane leaves, efficient inoculation of tissuecultured sugarcane plantlets with SCYLV, and variation in infection capacity and virulence of SCYLV. Additional studies are needed to further investigate the importance of SCYLV strains on a world-scale basis and to identify the genetic origin of this variation. Segregation for resistance exists in sugarcane progeny and resistance to infection by SCYLV appears to be a promising method to control yellow leaf (34). However, efficient screening of resistant sugarcane cultivars will have to take into account variation in infection capacity and virulence of SCYLV.

\section{ACKNOWLEDGMENTS}

This research was conducted during the thesis scholarship program of Youssef Abu Ahmad, supported by the Government of Syrian Arabic Republic and CENICAÑA in Colombia. We thank M.-J. Darroussat, R. Boisne-Noc, M. Payet, J.-F. Bousquet, E. Fernandez, R. Habas, and M. Muller for technical assistance; G. Labonne, J.-M. Lett, B. Lockhart, and N. Sauvion for fruitful discussions and suggestions regarding aphid rearing; B. Vercambre for Melanaphis sacchari aphid identification; AIPSA (Peru), CENICAÑA (Colombia), CERF (Réunion Island), COPERSUCAR (Brazil), and HARC (Hawaii) for supplying sugarcane cultivars used in this study; and S. Schenck, E. Mirkov, and J. Victoria for critical review of the manuscript.

\section{LITERATURE CITED}

1. Abu Ahmad, Y., Rassaby, L., Royer, M., Borg, Z., Braithwaite, K. S., Mirkov, T. E., Irey, M. S., Perrier, X., Smith, G. R., and Rott, P. 2006. Yellow leaf of sugarcane is caused by at least three different genotypes of sugarcane yellow leaf virus, one of which predominates on the Island of
Réunion. Arch. Virol. 151:1355-1371.

2. Abu Ahmad, Y., Royer, M., Daugrois, J.-H., Costet, L., Lett, J.-M., Victoria, J. I., Girard, J.C., and Rott, P. 2006. Geographical distribution of four Sugarcane yellow leaf virus genotypes. Plant Dis. 90:1156-1160.

3. Alegria, O. M., Chatenet, M., Girard, J.-C., Saldarriaga, S. A., Nuget, A., and Rott, P. 2000. First report of Sugarcane yellow leaf virus in Peru. Plant Dis. 84:1342.

4. Anstead, J. A., Burd, J. D., and Shufran, K. A. 2002. Mitochondrial DNA sequence divergence among Schizaphis graminum (Hemiptera: Aphididae) clones from cultivated and non-cultivated hosts: haplotype and host associations. Bull. Entomol. Res. 92:17-24.

5. Borg, Z., Moonan, F., Braithwaite, K., Mirkov, T. E., and Smith, G. 2001. Characterising the genetic diversity of sugarcane yellow leaf virus. Proc. Int. Soc. Sugar Cane Technol. Congr. 24:654-656

6. Chatenet, M., Delage, C., Ripolles, M., Irey, M., Lockhart, B. E. L., and Rott, P. 2001. Detection of Sugarcane yellow leaf virus in quarantine and production of virus-free sugarcane by apical meristem culture. Plant Dis. 85:1177-1180.

7. Comstock, J. C., Irey, M. S., Lockhart, B. E. L., and Wang, Z. K. 1998. Incidence of yellow leaf syndrome in $\mathrm{CP}$ cultivars based on polymerase chain reaction and serological techniques. Sugar Cane 4:21-24

8. D'Arcy, C. J., and Domier, L. L. 2005. Luteoviridae. Pages 891-900 in: Virus Taxonomy. Eighth Report of the International Committee on Taxonomy of Viruses. C. M. Fauquet, M. A, Mayo, J. Maniloff, U. Desselberger, and L. A. Ball, eds. Elsevier Academic Press, London.

9. Dedryver C.-A., Riault, G., Tanguy, S., Le Gallic, J. F., Trottet, M., and Jacquot, E. 2005. Intra-specific variation and inheritance of BYDV-PAV transmission in the aphid Sitobion avenae. Eur. J. Plant Pathol. 111:341-354.

10. Fontaniella, B., Vicente, C., Legaz, M. E., de Armas, R., Rodríguez, C. W., Martinez, M., Piñón, D., Acevedo, R., and Solas, M. T. 2003. Yellow leaf syndrome modifies the composition of sugarcane juices in polysaccharides, phenols and polyamines. Plant Physiol. Biochem. 41:1027-1036.

11. Gonçalves, M. C., Vega, J., Olivieira, J. G., and Gomes, M. A. 2005. Sugarcane yellow leaf virus infection leads to alterations in photosynthetic efficiency and carbohydrate accumulation in sugarcane leaves. Fitopatol. Bras. 30:10-16.

12. Gray, S. M., and Banerjee, N. 1999. Mechanisms of arthropod transmission of plant and animal viruses. Microbiol. Mol. Biol. Rev. 63:128-148.

13. Gray, S., and Gildow, F. E. 2003. Luteovirusaphid interactions. Annu. Rev. Phytopathol. 41:539-566.

14. Gray, S. M., Smith, D. M., Barbierri, L., and Burd, J. 2002. Virus transmission phenotype is correlated with host adaptation among genetically diverse populations of the aphid Schizaphis graminum. Phytopathology 92:970-975.

15. Grisham, M. P., Pan, Y.-B., Legendre, B. L., Godshall, M. A., and Eggleston, G. 2001. Effect of sugarcane yellow leaf virus on sugarcane yield and juice quality. Proc. Int. Soc. Sugar Cane Technol. Congr. 24:434-438.

16. Grisham, M. P., Pan, Y. B., White, W. H., Godshall, M. A., Legendre, B. L., and Comstock, J. C. 2002. Potential effect of yellow leaf syndrome on the Louisiana sugarcane industry. J. Am. Soc. Sugar Cane Technol. 22:125-126.

17. Izaguirre-Mayoral, M. L., Carballo, O., Alceste, C., Romano, M., and Nass, H. A. 2002. Physiological performance of asymptomatic and yellow leaf syndrome-affected sugarcanes in Venezuela. J. Phytopathol. 150:13-19.

18. Lehrer, A. T., Schenck, S., Fitch, M. M. M.,
Moore, P. H., and Komor, E. 2001. Distribution and transmission of sugarcane yellow leaf virus (SCYLV) in Hawaii and its elimination from seedcane. Proc. Int. Soc. Sugar Cane Technol. Congr. 24:439-443.

19. Lockhart, B. E. L., and Cronjé, C. P. R. 2000. Yellow leaf syndrome. Pages 291-295 in: A Guide to Sugarcane Diseases. P. Rott, R. A. Bailey, J. C. Comstock, B. J. Croft, and A. S. Saumtally, eds. La Librairie du Cirad, Montpellier, France.

20. Lucio-Zavaleta, E., Smith, D. M., and Gray, S. M. 2001. Variation in transmission efficiency among Barley yellow dwarf virus-RMV isolates and clones of the normally inefficient aphid vector, Rhopalosiphum padi. Phytopathology 91:792-796.

21. McCullagh, P., and Nelder, J. A. 1989. Generalized Linear Models. Second edition. Chapman and Hall, London.

22. Miller, W. A., and Rosochová, L. 1997. Barley yellow dwarf viruses. Annu. Rev. Phytopathol. 35:167-190.

23. Moonan, F., and Mirkov, T. E. 2002. Analyses of genotypic diversity among North, South, and Central American isolates of Sugarcane yellow leaf virus: evidence for Colombian origins and for intraspecific spatial phylogenetic variation. J. Virol. 76:1339-1348.

24. Moonan, F., Molina, J., and Mirkov, T. E. 2000. Sugarcane yellow leaf virus: an emerging virus that has evolved by recombination between luteoviral and poleroviral ancestors. Virology 269:156-171.

25. Moutia, J.-F. Y., and Saumtally, S. 2001. Diagnosis of sugarcane yellow leaf virus in cane juice and the effect of hot water treatment on its control. Proc. Int. Soc. Sugar Cane Technol. Congr. 24:444-450.

26. Porter, D. R., Burd, J. D., Shufran, K. A., Webster, J. A., and Teetes, G. L. 1997. Greenbug (Homoptera: Aphididae) biotypes: selected by resistant cultivars or preadapted opportunists? J. Econ. Entomol. 90:1055-1065.

27. Rassaby, L., Girard, J.-C., Lemaire, O., Costet, L., Irey, M. S., Kodja, H., Lockhart, B. E. L. and Rott, P. 2004. Spread of Sugarcane yellow leaf virus in sugarcane plants and fields on the Island of Réunion. Plant Pathol. 53:117-125.

28. Rassaby, L., Girard, J.-C., Letourmy, P., Chaume, J., Irey, M. S., Lockhart, B. E. L., Kodja, H., and Rott, P. 2003. Impact of Sugarcane yellow leaf virus on sugarcane yield and juice quality in Réunion Island. Eur. J. Plant Pathol. 109:459-466.

29. Scagliusi, S. M., and Lockhart, B. E. L. 2000. Transmission, characterization, and serology of a luteovirus associated with yellow leaf syndrome of sugarcane. Phytopathology 90:120-124

30. Schenck, S., Hu, J. S., and Lockhart, B. E. L. 1997. Use of a tissue blot immunoassay to determine the distribution of sugarcane yellow leaf virus in Hawaii. Sugar Cane 4:5-8.

31. Schenck, S., and Lehrer, A. T. 2000. Factors affecting the transmission and spread of Sugar cane yellow leaf virus. Plant Dis. 84:1085-1088.

32. Smith, G. R., Borg, Z., Lockhart, B. E. L., Braithwaite, K. S., and Gibbs, M. J. 2000 Sugarcane yellow leaf virus: a novel member of the Luteoviridae that probably arose by inter-species recombination. J. Gen. Virol. 81:1865-1869.

33. Vega, J., Scagliusi, S. M. M., and Ulian, E. C. 1997. Sugarcane yellow leaf disease in Brazil: evidence of association with a luteovirus. Plant Dis. 81:21-26.

34. Victoria, J. I., Avellaneda, M. C., Angel, J. C., and Guzmán, M. L. 2005. Resistance to Sugar cane yellow leaf virus in Colombia. Proc. Int. Soc. Sugar Cane Technol. Congr. 25:664-670.

35. Viswanathan, R. 2002. Sugarcane yellow leaf syndrome in India: Incidence and effect on yield parameters. Sugar Cane Int. 20:17-23. 